\title{
The Biodiversity Bargaining Problem
}

\author{
J. Rupert J Gatti* Timo Goeschl ${ }^{\dagger} \quad$ Ben Groom $^{\ddagger} \quad$ Timothy Swanson ${ }^{\S}$
}

(Running Title: The Biodiversity Bargaining Problem)

December 16, 2006

${ }^{*}$ Department of Economics, University of Cambridge.

${ }^{\dagger}$ Department of Economics, University of Heidelberg.

†Department of Economics, University College London.

${ }^{\S}$ Corresponding author: Department of Economics, University College London. tim.swanson@ucl.ac.uk. 


\title{
The Biodiversity Bargaining Problem
}

\begin{abstract}
The Convention on Biodiversity has arisen to facilitate cooperation between the North and South, capture the global value of biological diversity and, concomitantly, divide the cooperative surplus. We employ cooperative bargaining theory and Nash's 'rational threats' idea to cast light on the biodiversity bargaining problem. We show that destructibility of natural resources means; a) strategic threats are only credible in the South and; b) efficient contracts require payment for stocks of reserves. We then show that the Incremental Cost contract of the CBD, which does not accord with these findings, reflects institutional pre-commitment by the North.as a response to this perceived asymmetry.

Keywords: North-South Cooperation, Nash Bargaining, Convention on Biodiversity (CBD), Incremental Cost Contract, Institutional Commitment.

JEL Classification: Q15, Q16, Q21, O13, O34.
\end{abstract}




\section{Introduction}

The need for global cooperation for the conservation of biological diversity has long been understood [2] . The management of this global resource is particularly problematic on account of the important asymmetries that exist across societies. Some parts of the world are highly endowed with biodiversity (here, the "South") while others have very little (the "North"). There are also other important asymmetries between these parts of the world. The North is relatively well-endowed with the human capital required for technological innovation, and conducts most of the research and development $(\mathrm{R} \& \mathrm{D})$ that translates diverse genetic resources into important intermediate goods.[22] The South on the other hand contains few of these sorts of resources, and conducts little of the R\&D in this industry. Finally, these differences in endowments are also significant because some forms are fugacious and relatively indestructible (information), while others are highly vulnerable and irreversibly so (biodiversity). These asymmetries across endowments and industries result in an unbalanced bargaining process in which each party is negotiating from a position of relative strength in some respects, and weakness in others. This stylisation frames the questions we ask here: What are the factors that would determine the division of the cooperative surplus in such a setting? And, do these factors explain the contractual terms actually observed within this context?

The bargaining problem is starkest in the biotechnology sector. Here, diverse genetic resources in the South provide important stocks of information over which search is conducted for solutions to important problems in the life sciences[20][8]. Then research and development (R\&D) is undertaken in the pharmaceutical and agricultural industries of the North to refine these solutions and to capture them within marketable intermediate goods (pills and seeds, respectively). Finally, these intermediate goods can be returned to both North and South to advance production and enhance social welfare. Thus, cooperation in combining the endowments of North and South can result in significant welfare gains for both societies, so long as both can agree on the basis by which these gains will be distributed.

What complicates this mutual interdependence between North and South is that, due to the informational nature of the goods exchanged, market prices, and therefore simply trade, cannot be relied upon to coordinate the activities of the parties concerned. A different set of institutions is required to allow the potential gains from cooperation to be realized. In response to this challenge and the ongoing loss of biodiversity over the last decades [16], countries agreed in the early 1990s to create international institutions for the provision of this global public good and its services. The Convention on Biological Diversity (CBD) in 1992 and its financial instrument the Global Environment Facility (GEF) represent the primary international agreements for implementing cooperation in regard to this global good. ${ }^{1}$

In this paper we ask the question: What factors determined the specific structure of the bargain that was made for biodiversity? To do this we use cooperative bargaining

\footnotetext{
${ }^{1}$ Recently an additional international instrument: the International Treaty on Plant Genetic Resources for Food and Agriculture came into force. Its future impact is unclear since i) important countries (e.g United States, China and Brazil) have not signed or ratified and; ii).key mechanisms of the Treaty, (e.g. the financing mechanism) have not been defined. The TRIPS agreement is not silent on this issue either. Section 27(b) extends intellectual property rights to lifeforms and genetic material, and encourages sui generis property rights systems for traditional knowlege and indigenous flora and fauna.
} 
theory to characterise the biodiversity bargaining problem (BBP) between North and South. This characterisation makes plain that, while the pursuit of the joint gains from cooperation explains the existence of these international institutions, it does not explain the specific division of the cooperative surplus between North and South. We demonstrate here that there are many possible efficient and feasible solutions to the biodiversity bargaining problem, and that the contractual terms of the existing institutional solution represent a very special case - an extreme point contract. We then examine how the asymmetries in endowments might explain the derivation of this particular contract. We find that the physical assymetries cannot explain this outcome. Instead we find that the actual contractual terms are better explained by reference to an institutional asymmetry that has enabled one player to precommit to its preferred pay-off in anticipation of the uneven nature of the bargaining problem.

What are the contractual terms that this paper is about? In the case of biodiversity, these terms are found in the CBD and its supporting financial mechanism, the GEF. These international environmental agreements established the framework within which the North and South agreed that biodiversity should be provided as a global good, and further established the basis for determining how states providing biodiversity should share in the benefits of the global public good they provide. Implicit within the terms of the CBD is the idea that the South must provide much of the biodiversity resource, and the focus of the agreement is the means by which they will be compensated for doing so - the answer to which is found in the concept of incremental costs [IC]:

'[the North] shall provide new and additional financial resources to enable [the South] to meet the agreed full incremental costs to them of implementing measures which fulfil the obligations of this Convention'. [Art. 20, CBD].

The meaning of the term "incremental costs" is further defined within the founding instrument of the GEF as:

"[the costs of] additional national action beyond what is required for national development [the baseline] that imposes additional [or incremental] costs on countries beyond the costs that are strictly necessary for achieving their own development goals, but nevertheless generates additional benefits that the world as a whole can share ..."2

Thus, the terms of the agreements establishing the CBD and the GEF impose an obligation on those states hosting biodiversity to supply it for the global good, and dictate that the North shall share the benefits of such public goods with the South by paying the amounts required to compensate it for the costs of its participation.

As the subsequent sections demonstrate, this concept of IC as the solution to the BBP is neither obvious nor preordained. At the same time, its emergence points to key characteristics of the contracting process for providing global public goods such as biodiversity. Here we attempt to explain the nature of the biodiversity bargaining problem, and the means by which bargaining in this arena has led to the institutions we observe. The specific contributions of this paper are threefold. One is to apply cooperative bargaining theory within the biodiversity context, demonstrating the bargaining frontier and the wide range of efficient

\footnotetext{
${ }^{2}$ GEF/C.7/Inf.5: para.2 \& GEF/C.2/6 para.2, see [13]
} 
contracts available for attaining it. The second is to use the insights of bargaining theory to characterize the observed incremental cost contract as an extreme point contract. Thirdly, by extending the bargaining situation to include the use of 'rational threats' [17] and 'precommitment', the paper shows that the existing contractual terms can be explained as a possible outcome of the uneven bargaining in this context. The asymmetry in physical endowments explains the existence of uneven bargaining power, and allows one of the agents to claim a greater share of the bargaining surplus. This cannot explain the existing contract, but it can explain the reason for exercising pre-commitment. An asymmetry in institutional characteristics - specifically, the order of moves - is able to explain the existing nature of the contract, and is itself explained as a rational response to the bargaining power conferred by rational threats.

In the following section we present a model of biotechnology, R\&D and land use in a North-South world and describe the bargaining problem between a 'technology-rich' North and a 'gene-rich' South. Section 3 considers the Nash Bargaining Game between North and South and the role of strategic threats in determining specific solutions. The conditions for the existence of rational threats are established and illustrated. Section 4 then highlights how the nature of the international bargaining process over biodiversity in the presence of rational threats can help explain the specific resolution of the biodiversity bargaining problem in the form of the CBD. Section 5 concludes.

\section{The Biodiversity Bargaining Problem (BBP)}

\subsection{The Model: Biotechnology, R\&D and Land Use}

Here we develop a model to explore the nature of Nash bargaining between two very distinctive parts of the world, termed North and South. This is in line with previous models in this context (e.g. [5][14][11][18] ). We stylise these agents as being distinctive in several important respects: capital endowments, industrial structures and land use choices. The asymmetry in capital endowments refers to the relative richness of the North in human capital but poverty in natural (genetic) capital, while the South retains its relative richness in genetic capital but without a very rich human capital base. The differential industrial structure refers to the unique existence of an $R \& D$ sector in the North specialised in the production of intermediate goods containing embedded innovations, in contrast to the focus on primary production in the South. The distinct land use choices refer primarily to the South's unique capacity for supplying a biodiversity reserve sector, but also to the fact that the South's alternative land uses include both an intensive agricultural sector that is technology-dependent and a traditional sector which is not; whereas the North's land uses are relatively undifferentiated and involve mainly various forms of modern intensive agricultural production. ${ }^{3}$ The biodiversity bargaining problem arises from the dependence of the North on the South for a supply of biodiversity reserves (to maintain an R\&D sector), and the dependence of the South on the North for a supply of intermediate goods (to maintain

\footnotetext{
${ }^{3}$ Not only do we assume that these differences currently inhere, but we also assume that these stylised facts are inalterable, i.e. the South is the only possible source of biodiversity and the North is the only possible source of R\&D. This implies that biodiversity losses are irreversible and that existing human capital endowments cannot be significantly altered within the timescale of this analysis
} 
an intensive sector). We now set out the basic assumptions of our model, to make clear the asymmetries on which the following discussion is based.

\section{ASSUMPTION 1 (Asymmetries in Agents' Endowments):}

The parties engaged in bargaining are two, and are different in several important respects. The North: 1) The North has a capital endowment consisting primarily of human capital with a much lower level of natural capital; 2) The North's human capital is utilised within its R\&D sector in combination with genetic resources from the South to produce intermediate goods within which innovations are embedded; and 3) The North has no land use choice regarding the retention of genetic resource reserves (as losses of genetic resources are irreversible) but only has choices over different productive uses of agricultural lands, one use employing the intermediate goods from the R\&D sector and the other not. The South: 1) The South has a capital endowment consisting primarily of natural capital and a much smaller amount of human capital. 2) The South's natural capital consists of reserve lands endowed with diverse genetic resources which produce a flow of information which is useful when embedded within the intermediate goods of the R\&D sector of the North. 3) The South's land use choice consists of both reserve retention and two methods of agricultural production, one of which uses the intermediate goods from the North and the other which does not.

We examine the interdependence between these two spheres as a stylised representation of the global agricultural biotechnology industry, in which genetic resources emanating from a 'reserve' sector in the South are the major input into a plant breeding sector situated exclusively in the North. The plant breeding sector relies upon the skilled human capital endowment in the North to undertake research and development activities based upon these genetic resources. This $R \& D$ sector produces innovations in the form of new seeds, within which the information from the genetic resources is embedded. These intermediate goods then can be used in intensive agricultural sectors in either the North or South. Of course, the expansion of intensive agriculture in the South is a means by which cooperative surplus might be shared, but it is also in conflict with the objective of retaining maximum amount of genetic resources for the R\&D sector. The problem we examine is how the North and

South might simultaneously determine land uses and distribute joint surplus within such an asymmetric bargaining environment.

We now describe the details of North-South interaction within this asymmetric environment, and both the centralised and decentralised bargaining solutions to the biodiversity bargaining problem.

\subsubsection{The North}

The North is endowed with basic natural capital (land) but a rich human capital base. The Northern land endowment $\left(L_{N}\right)$ represents land that has been cleared of biological diversity and is allocated between two alternative land uses: a technologically inactive and relatively unskilled baseline sector and an intensive and technologically-active agricultural sector. We assume that all land is homogeneous for a given use, so marginal products will be constant. Baseline production in the North produces final output by the application of an unvarying technology to some part of the land endowment. It therefore represents a base-line production sector in the sense that its productivity is not associated with the outcome of the bargaining 
process, or any choices made by the South. Production in this baseline sector is represented by the net output function:

$$
y_{N}^{b}=b l
$$

where $l$ is the land devoted to this sector and $b$ is a net productivity parameter ${ }^{4}$. We take final output as the numeraire.

The other productive sector in the North is technologically more active, and reliant upon decisions taken in the South. This "intensive" sector produces final output, $y_{N}^{i}$, using seeds, $n$, developed within the R\&D sector. ${ }^{5}$ The R\&D sector operates by combining the North's human capital with the genetic resources from the South to generate productivity-enhancing innovations. The dependence on the South is captured in the assumption that innovations arrive with a probability which is positively affected by the South's choice of the size of the Reserve sector, $R$, in the South. ${ }^{6}$ An innovation has the impact of effectively causing a land-augmenting productivity increase in the intensive sector, captured by the function, $\pi(R)$, which pre-multiplies the intensive sector production function. Thus, final output in the intensive sector captures the interdependent/joint nature of production as it is a function of HYVs from the North and Reserves in the South. Intensive production is represented by the net output function ${ }^{7}$ :

$$
y_{N}^{i}=\pi(R) n, \quad\left(\pi(0)=b, \pi^{\prime}(R)>0, \pi^{\prime}(0)=\infty, \pi^{\prime \prime}(R) \leq 0\right)
$$

The land constraint is $L_{N}=n+l$ and total output is therefore represented by:

$$
y_{N}=\pi(R) n+b\left(L_{N}-n\right)
$$

The costs of R\&D are assumed to rise with the quantity of the intermediate output, i.e. $c(x)$, where $c(0)=0, c^{\prime}() \geq 0,. c^{\prime \prime}()>$.0 . These increasing costs are attributable to the need to draw larger amounts of skilled labour into the sector at larger scales of production. ${ }^{8}$ There is no significant amount of land used in the sector. The R\&D sector can supply seed to the South (s) as well as the North so the total quantity of seed produced is equal to: $x=n+s$. We assume that the point of the $\mathrm{R} \& \mathrm{D}$ sector is to increase productivity over the baseline. From Equations (1) and (2) it is clear that when $R=0$ both the baseline and the

\footnotetext{
${ }^{4}$ This represents the output net of costs valued in terms of output. This represents a constant returns to scale production technology. The coefficient $b$ can be thought of as a being equal to a value $(e-d)$, where $e$ represents the productivity of land devoted to this sector and $d$ represents the costs. Thus, setting $b=0$ is the same as assuming a zero profit condition for the baselne sector. It may be instructive to think of this sector as being a capital intensive but low-technology sector, such as "organic food production"; however, the only function the baseline sector serves is to supply a threshhold level of production in the event of conflict with the South.

${ }^{5}$ We assume a fixed 1 to 1 relationship between seed and land, hence the amount of land used in intensive production is equal to $\mathrm{n}$.

${ }^{6}$ The reserves are best thought of as representing traditional landraces in the context of HYVs. A similar interdependence could be discussed concerning tropical forests and the pharmaceutical industry although this would not easily capture the important land-use issues of interest here.

${ }^{7}$ Where $\pi^{\prime}($.$) is the first derivative of the function and \pi^{\prime \prime}($.$) is the second derivative with respect to its$ argument. This notation holds for the remainder of the paper and for other functions.

${ }^{8}$ The relationship between the scale of production and the scale of the required inputs into R\&D is wellknown in the biotechnology context. This is attributable to the observation that larger scales of use induce a more rapid evolutionary response, and thus hasten technological obsolescence [7], [8], [9].
} 
intensive sectors are equally productive. However, when $R>0$ the functional forms ensure that the intensive sector is preferred to the baseline sector over some range, and $l$ is the residual use of land. Lastly, the North can make a transfer payment, $T$, to the South which may be dependent upon the levels $n$ and $s$ and other variables; so, for example, this transfer might be negative in quantity, and representative of the value transferred by the South for the intermediate good of the North, or positive and representative of the value transferred by the North for reserves in the South.

The utility function for the North represents all sectors and payments and is given by:

$$
U_{N}(n, s, t)=(\pi(R)-b) n-c(n+s)-T+b L_{N}
$$

\subsubsection{The South}

The South is endowed with a rich natural capital base and a basic labour endowment. The South is endowed with land, $L_{S}$. In contrast to the North, this land endowment includes substantial amounts of unconverted 'reserve' land that is rich in genetic diversity. Southern land can be maintained as Reserves with area $R$, or converted to either a traditional sector, $t$, or to an intensive agricultural sector using seed imported from the North, $s$. As above, land is homogenous regarding a particular use, and so marginal productivity is constant.

Production in the traditional sector occurs via a fixed proportions production function based on labour and land and is unaffected by technological innovation. Gross output in the traditional sector is $t$ and traditional production incurs a labour-related cost $k(t)$, (where $k(0)=0, k^{\prime}(\cdot)>0, k^{\prime \prime}(\cdot)>0$ as labour is drawn from other parts of the economy such that

the net output function is

$$
y_{S}^{t}=t-k(t)
$$

In the intensive sector, the South benefits from the presence of Reserves, $R$, in precisely the same way as the North in that productivity is augmented by the arrival of intermediate

goods from the R\&D sector. The joint nature of final output from the intensive sector is represented by an analogous production function:

$$
y_{S}^{i}=\pi(R) s
$$

Southern utility is then given by:

$$
U_{S}(n, s, t)=\pi(R) s+t-k(t)+T,
$$

which is maximised with respect to $t, s$ and the Southern land constraint: $L_{S}=R+t+s$, where $R$ is the residual land allocation and the transfer $T$ has the same interpretation as in the North.

This simple model provides each part of the world with a land use allocation problem that exists in isolation (i.e. in the absence of any recognised inter-linkages) and also a much more interesting problem which exists in the presence of this interdependence. This set-up is 
intended solely for the purpose of establishing a baseline land use allocation that would exist in each part of the world when acting independently, and another when acting cooperatively. ${ }^{9}$

In the following section we characterise the conflict point of this negotiation and the extent of the cooperative gains.

\subsection{North-South Conflict and Cooperation}

\subsubsection{The Conflict Point: $(s=0, T=0)$}

The conflict point provides the benchmark against which all bargaining solutions are measured. Here the conflict point represents an 'Autarky' outcome in that it is characterised by: i) the absence of seed sales from North to South: $s=0$; and ii) the absence of North-South transfers $(T)$. Consequently the South fails to internalise the value of reserves $(R)$ and there is an under-supply of this global good. Under these circumstances the problems of the North and South are as follows ${ }^{10}$ :

THE SOUTH: The South maximises utility with respect to $t$.

$$
\begin{gathered}
\max _{t} U_{S}(s=0, T=0)=t-k(t) \\
\text { s.t. : } L_{S}=t+R \text { and } 0 \leq t \leq L_{S}
\end{gathered}
$$

If $k^{\prime}(0) \leq 1<k^{\prime}\left(L_{S}\right)$, the South's optimal use of land under Autarky, $t^{a}$, will be an interior solution and satisfy the first order condition:

$$
1-k^{\prime}\left(t^{a}\right)=0
$$

Let $R^{a}=L_{S}-t^{a}$ be the South's Reserves under Autarky.

THE NORTH: The North takes the behaviour of the South as given and maximises utility over its choice of $n$ and $l$. The North's problem is as follows:

$$
\begin{gathered}
\max _{n} U_{N}(s=0, T=0)=(\pi(R)-b) n-c(n)+b L_{N} \\
\text { s.t. : } 0 \leq n \leq L_{N}
\end{gathered}
$$

\footnotetext{
${ }^{9}$ Specifically, it is assumed without any real loss of generality that the only sectors with rising marginal costs are the intermediate goods sector in the North and the traditional agriculture sector in the South. These assumptions serve no purpose other than to provide a determinant solution to the baseline problem in each region, i.e. the optimal choice of each region if acting in isolation. In order to provide such a solution, rising marginal costs are assumed to inhere in the labour markets of that sector where production is most labour-intensive (R\&D in the North, traditional agriculture in the South). This supplies the conflict point from which the analysis is initiated, but there are no other implications that flow from this assumption.

${ }^{10}$ We assume that the North and the South are single entities. This reflects the idea that the countries in the South are sufficiently large to influence the North in the bargaining solution.
} 
If $c^{\prime}(0)=0$ and $c^{\prime}\left(L_{N}\right)>\pi\left(L_{S}\right)$, the North's optimal land use, $n^{a}$, will be an interior solution satisfying the first order condition:

$$
\pi\left(R^{a}\right)-b-c^{\prime}\left(n^{a}\right)=0
$$

This Autarky problem shows the interdependence of North and South, in that the North is dependent upon the South's selection of reserves to generate productivity in any intensive sector, while the South has no reason to supply reserves in the absence of a flow of intermediate goods from the North. For this reason, the South in Autarky maximises production in its traditional sector, which serves to lower the marginal productivity of the North's intensive sector $(n)$.

As either region always has the opportunity of production in isolation, the Autarky solutions will constitute the Conflict Point in any bargaining game over land use and distribution ${ }^{11}$. Furthermore, we characterise the the Autarky solution by the land allocations and payoffs $\left(t^{a}, R^{a}, l^{a}, n^{a}\right)$ and $\left(U_{S}^{a}, U_{N}^{a}\right)$ and describe it as an 'interior solution' whenever $R^{a}, t^{a}, l^{a}, n^{a}>0^{12}$.

\subsubsection{First Best (Social Planner) Allocation}

The social planner problem involves the maximisation of global surplus with respect to the land allocations $n, s$ and $t$. The problem can be stated as follows:

$$
\begin{gathered}
\max _{n, s, t} U(n, s, t)=U_{S}+U_{N}=\pi(R)(n+s)-b n+t-c(n+s)-k(t)+b L_{N} \\
\text { s.t. } R=L_{S}-s-t \text { and } l=L_{N}-n \\
\text { and } s, n, t, l, R \geq 0
\end{gathered}
$$

A complete characterisation of the optimal solution is unnecessary for our purposes, however Lemma 1 provides an analysis of the comparative statics of the optimal and Autarky solutions.

LEMMA 1: If the Autarky solution is interior, and the social planner wishes to hold positive levels of Reserves (i.e. $R^{*}>0$ ) then:

a) intensive agricultural production will always be positive, i.e. $\left(n^{*}+s^{*}\right)>0$;

b) optimal traditional production in the South will be less than under Autarky, (i.e. $\left.t^{*}<t^{a}\right)$

c) whenever there is intensive production in the North, the optimal Reserve sector increases with global intensive agriculture

$$
\text { (i.e. } \left.\quad R^{*}>(<) R^{a} \Longleftrightarrow n^{*}+s^{*}>(<) n^{a}\right) ; \quad \text { and }
$$

\footnotetext{
${ }^{11}$ Welfare in the South under autarky, $U_{S}^{a}$, is defined as $U_{S}^{a}=t^{a}-k\left(t^{a}\right)$, and welfare in the North is defined by $U_{N}^{a}=\left(\pi\left(R^{a}\right)-b\right) n^{a}-c\left(n^{a}\right)+b L_{N}$.

${ }^{12}$ Sufficient conditions for the existence of an interior solution to the Autarky problem are that $k^{\prime}(0)<$ $1<k^{\prime}\left(L_{S}\right), c^{\prime}(0)=0$ and $c^{\prime}\left(L_{N}\right)>\pi\left(L_{S}\right)-b$.
} 
d) if profits are equal to zero in the baseline sector $(b=0)$, then $s^{*}>0$ only when $n^{*}=L_{N}$.

PROOF: Whenever $L_{S}>R^{*}>0, \frac{\delta R}{\delta S}=\frac{\delta R}{\delta T}=-1$ and the first order Kuhn-Tucker conditions yield:

$$
\begin{gathered}
s^{*} \geq 0: \pi(R)-\pi^{\prime}(R)\left(s^{*}+n\right)-c^{\prime}\left(n+s^{*}\right) \leq 0 \\
n^{*} \geq 0: \pi(R)-b-c^{\prime}\left(n^{*}+s\right) \leq 0 \\
t^{*} \geq 0: 1-\pi^{\prime}(R)(n+s)-k^{\prime}\left(t^{*}\right) \leq 0
\end{gathered}
$$

with the inequalities in Eqns (15) and (16) strict equalities whenever $l^{*}=L_{N}-n^{*} \geq 0$. Hence the proof follows in parts: a) From Equation (17) if $\left(n^{*}+s^{*}\right)=0$ then $t^{*}=t^{a}$ and so $R^{*}=R^{a}$. Comparing Equations (13) and (16) when $R^{*}=R^{a}$, we have that $\left(n^{*}+s^{*}\right)=$ $n^{a}>0$, which is a contradiction; b) If $t^{*}=0$ then $t^{*}<t^{a}$ by assumption. If $t^{*}>0$ then $1-k^{\prime}\left(t^{*}\right)=\pi^{\prime}\left(R^{*}\right)\left(n^{*}+s^{*}\right)>0=1-k^{\prime}\left(t^{a}\right)$, thus $t^{*}<t^{a}$ as $k^{\prime \prime}()>$.0 ; c) Comparing Equations (13) and (16), if $n^{*}>0$, then $n^{*}+s^{*}>(<) n^{a} \Longleftrightarrow R^{*}>(<) R^{a}$; d) Given $b=0$, comparing Equations (15) and (16); $n^{*}<L_{N} \Longrightarrow s^{*}=0$ and therefore $R^{*}>R^{a}$.

Lemma 1(b) shows that the optimal size of the traditional sector in the South is smaller than under Autarky, however 1(c) shows that the overall level of Reserves will rise and fall with the size of the global intensive sector. How the socially optimal allocation compares with the Autarky state will depend upon the parameters of the model, particularly the relative productivity of the baseline sector in the North and the traditional sector in the South. A low value for $b$ increases the likelihood that the socially optimal level of Reserves is higher than under Autarky. Lemma 1(d) shows that in the extreme case where the profits from the baseline sector are equal to zero $(b=0)$ the ambiguity is resolved and $R^{*}>R^{a}$ whenever the North's baseline sector remains active. In sum, the social planner is reluctant to have intensive agriculture in the South due to the loss of socially valuable Reserves this land use would entail, and where $b=0$ the social planner would choose specialised regional functions: intensive production in the North and Reserves in the South. This is indicative of the importance of cooperation in this context: when acting separately each pursues a similar mix of relatively unproductive activities, when acting cooperatively the two generate a vertical industry in which the South specialises in Reserves and the North specialises in R\&D. The incentive to cooperate is found in the enhanced productivity emanating from the new industry. We turn now to defining the level of that cooperative surplus.

\subsubsection{The Cooperative Surplus}

Defining optimal welfare under the social planner solution by $U^{*}=U_{N}^{*}+U_{S}^{*}$ allows us to define the extent of the social gains from cooperation, $U^{C}$, as the difference between the welfare under the social planner and that under Autarky:

$$
U^{C}=U^{*}-\left(U_{N}^{a}+U_{S}^{a}\right)
$$

Clearly, as the social planner is always able to select the Autarky outcome, $U^{C} \geq 0$. From Lemma 1, when the Autarky solution is interior then $t^{*}<t^{a}$ and it follows that the inequality is strict - so there exist strictly positive gains from cooperation. Figure 1 shows the Autarky 
and optimal outcomes. $U^{*}$ is any point on the welfare frontier. $U^{a}$ is the conflict point. The set of efficient distributions is termed the bargaining frontier, since the parties are able to achieve any point along this frontier so long as they can agree on which point they wish to attain. Although the Social Planner is not concerned with the distribution of cooperative gains from biodiversity preservation, a system of lump sum transfers ordered by the Social Planner can facilitate any desired distribution.

[INSERT FIGURE 1 ABOUT HERE]

Now that the nature of the biodiversity bargaining problem has been established, the indeterminancy of the solution is obvious. Each one of the points along $U^{*}$ can be sustained as the Nash Equilibrium of a cooperative bargaining game ${ }^{13}$. Choosing among these Nash equilibria depends upon the specifics of the bargaining process: the individual characteristics of the two agents and the institutions that determine their interaction. We turn now to the theoretical solutions to this problem and their relation to existing institutions.

\section{Solutions to the BBP}

Now that we have laid out the fundamental structure of the biodiversity bargaining problem, we can move towards a discussion of how the problem might be determined. To this end we first illustrate the family of solutions to a conventional Nash Bargaining Game (NBG). We then discuss how the solution might be rendered determinant. This leads to a discussion in subsequent sections of the implications of this bargaining structure and the implied location of bargaining power for the choice of institutions to uphold the solution to the BBP in practice. We conclude by relating these discussions to the actual contractual outcome observed in the context of biodiversity.

\subsection{Nash Bargaining Solution and Contract}

Any point on the bargaining frontier can be the solution to an asymmetric fixed threat Nash Bargaining Game (NBG). The general form of the solution to a NBG is a point $\left(U_{N}, U_{S}\right)$ which maximises:

$$
\left(U_{N}-U_{N}^{a}\right)^{\alpha}\left(U_{S}-U_{S}^{a}\right)^{(1-\alpha)} \text { s.t. } U_{N}+U_{S}=U^{*}
$$

where $\alpha \in[0,1]$ denotes the relative bargaining strength of the North. The solution gives $U_{N}^{*}=(1-\alpha) U_{N}^{a}+\alpha\left(U^{*}-U_{S}^{a}\right)$ and $U_{S}^{*}=\alpha U_{S}^{a}+(1-\alpha)\left(U^{*}-U_{N}^{a}\right)[17]$.

Given that there is no uncertainty or asymmetry of information between the agents in this model, an optimal contract can be constructed that would support any distribution of the gains from cooperation between North and South. According to Nash cooperative bargaining theory, the actual solution specified by the contract will depend upon the relative bargaining power of the two regions and the structure of the bargaining process. Bargaining power may derive from many factors, including differences in physical endowments. These physical and institutional factors determine relative bargaining power and hence the respective shares achieved by the parties within the bargaining process.

The most extreme possibility is that there is no sharing of cooperative surplus within the bargaining game. Contracts supporting distributions that correspond to the limits of the

\footnotetext{
${ }^{13}$ See e.g. Example 1 below.
} 
bargaining frontier, in which one party is devoid of all bargaining power, are described as extreme point contracts. Such contracts must satisfy the participation constraint: the contracted payoff must be greater than or equal to the conflict payoff $\left(U_{S}^{a}, U_{N}^{a}\right)$. More generally, optimal contracts may be designed that will support any distribution of the surplus that meet or exceed the participation constraints of the parties.

Proposition 1 describes the two extreme point contracts, and a general contract that could uphold any solution to an asymmetric NBG. ${ }^{14}$ The following contracts contain lumpsum transfers to satisfy participation contraints and to uphold the contracted division of surplus:

\section{PROPOSITION 1 (Optimal Contracts for solution of the BBP):}

a) Extreme Point ( $\mathrm{S}$ to $\mathrm{N}$ ): The optimal contract when the North has no bargaining power is for the South to specify the contractual terms $n^{*}, s^{*}$ and $t^{*}$ and the transfer:

$$
-T=T_{S}(n, s)=\left[\pi\left(R^{*}\right)-b\right](-n)+c(n+s)+\left[U_{N}^{a}-b L_{N}\right]
$$

where $R^{*}=L_{S}-s^{*}-t^{*}$.

b) Extreme Point ( $\mathrm{N}$ to $\mathrm{S}$ ): Inversely, the optimal contract when the South has no bargaining power is for the North to specify the contractual terms $n^{*}$ and $s^{*}$ and the transfer:

$$
T=T_{N}(t)=\int_{t}^{t^{a}}\left[1-k^{\prime}(z)\right] d z-\pi\left(L_{S}-s^{*}-t\right) s^{*}
$$

c) General ( $\mathrm{N}$ to $\mathrm{S}$ ): If framed as an offer by $\mathrm{N}$ to the $\mathrm{S}$, the optimal contract to uphold an asymmetric Nash bargaining solution would have North specify the contractual terms $s^{*}$ and $n^{*}$ and the transfer:

$$
T_{N}(t)=\int_{t}^{t^{a}}[1-k(z)] d z-\pi\left(L_{S}-s^{*}-t\right) s^{*}+(1-\alpha) U^{C}
$$

PROOF: See Appendix A.

There is already quite a lot of content in this Proposition (see Figure 1). Proposition 1(a) states that the extreme point contract offered by the South will specify $\left(U_{S}^{E}, U_{N}^{a}\right)$ in terms of Figure 1. Proposition1(b) states that the extreme point contract offered by the North will specify $\left(U_{S}^{a}, U_{N}^{E}\right)$. Each extreme point contract is optimal in the sense that it allows the agents to attain the bargaining frontier, but each merely compensates the party receiving the offer for the costs of its participation. These extreme point outcomes may result from the bargaining process where all the bargaining power resides in either the North or the South, respectively. ${ }^{15}$ Alternatively, it is also possible that the extreme point outcome may result from a procedure independent of the bargaining process. This may occur where the identity of the party making the offer of the extreme point contract is determined by some institutional or structural factor, that pre-determines the contractual outcome in advance of the bargaining process. In this respect it is important to note that the mechanism

\footnotetext{
${ }^{14}$ Within this framework, the party making the offer of the contract holds the residual rights to the cooperative surplus. In this example, that agent is assumed to be the $\mathrm{N}$ but the analysis is the same should the contract be structured as an offer from the $\mathrm{S}$ to the $\mathrm{N}$.

${ }^{15}$ To see an example of this for the Nash Bargaining outcome see Example 1 and evaluate (19), below, and the welfare outcomes for $\alpha=1$ and $\alpha=0$.
} 
establishing the optimality of such contracts does not rely on any particular power distribution. In fact, any and all distributions of bargaining power are capable of supporting these extreme point contracts, so long as the party concerned has control over the contract-making procedure.

In contrast, Proposition 1(c) shows the nature of the contract which specifies the asymmetric Nash solution to the bargaining game, depending on the prevailing distribution of bargaining power, $\alpha \in[0,1]$. This general form of contract which happens to be framed as an instance in which the North makes the offer to the $\mathrm{S}$ has three components. The first component compensates the South at the margin for choosing values of $t$ other than $t^{a}$, the second represents a transfer of surplus to the North (reflecting the idea that the residual rights lie with the party offering the contract, here the North). Together these terms ensure that the South is indifferent to any choice of $t$, including $t^{*}$, and push the South back to its autarky level of welfare. The last term represents the sharing of cooperative surplus induced by the relative power distribution. Depending upon that power distribution, any point along the bargaining frontier is a possibility. Unlike the extreme point contracts, this form of contract provides incentives for the opposite party (here, the South) to adhere to the contracted division of surplus. In this case the identity of the party offering the contract is irrelevant and the outcome is wholly dependent upon the relative bargaining power of the two parties ${ }^{16}$.

This section has demonstrated that the division of the cooperative surplus is not determinant within the structure of the bargaining game as set forth above. The entire range of efficient solutions remains possible, depending upon the structure of the bargaining process and/or depending upon the relative bargaining power of the parties within the process. We turn now to examine how the solution to the problem might be rendered determinant.

\subsection{Nash Bargaining with Variable Threats: Strategic Destruc- tion}

There are two currently unspecified structural elements to this problem that will contribute to the determination of a solution. The first is the structure of the bargaining process. How is the structure of the bargaining process constructed? Which party is the beneficiary? The second concerns the distribution of relative bargaining power between the parties. What is the distribution of power? What determines this distribution? Which party is the beneficiary? In this section we commence with a discussion of the latter issue, then in section four we turn to consider the structure of the bargaining process.

\subsubsection{Rational Threats in the BBP}

Here we investigate the distribution of bargaining power within the BBP, and how it is determined. One feature of many solution concepts to bargaining games, including the $\mathrm{NBG}$, is that the value received by one player (e.g. $U_{i}^{*}$ ) is not only increasing in the value of any outside option available to that player $\left(U_{i}^{a}\right)$ but also increasing in the maximum value of cooperation to the other player $\left(U_{j}^{*}-U_{j}^{a}\right)$. This is the bargaining power implicit in

\footnotetext{
${ }^{16}$ The transfers effectively linearise the bargaining frontier and embody the assumption of costless surplus transfer. For brevity we ignore the interesting case in which this linearisation is not possible. We thank an anonymous referee for this comment.
} 
the capacity for shifting the other player's perception of the bargaining game. The power this confers can be readily observed in the solution concept above. In essence, any actions available to one player that can increase the value of cooperation to the other player, ${ }^{17}$ without a negative impact upon their own outside option, increases the payoffs to that player within the cooperative bargaining game. It does so by creating a viable strategy by which the player would be able to reduce the other player's potential benefits more than their own, if the game were to be played noncooperatively, and so makes it possible to use this "threat" as the basis for more power within the cooperative game. The strategic use of "rational" threats to maximise payoffs in this way was first analysed by Nash. [17]. ${ }^{18}$

In order to determine the respective endowments of bargaining power in this context, we need to assess the availability of such rational threats to either party within our NBG. Our portrayal of a 'gene rich' South and a 'technology rich' North is one of specialised yet interdependent regions. It would seem that either party would be able to threaten withdrawal of cooperation within such an asymmetric bargaining situation: the North could threaten to reduce R\&D while the South could threaten to limit the supply of Reserves ${ }^{19}$. In either instance the threat would consist of a real action that might cause the bargaining frontier to shift inwards (without impacting the outside option of the threat-maker). So, at first glance it would appear that the asymmetric endowments would result in equivalent and reciprocal threat capacities, and so no real bargaining advantage.

However, a necessary condition for the credibility of threats in any application of the NBG is that parties must be able to commit to their threats, via irreversible actions ${ }^{20}$. One obvious means of making a credible commitment is for the party concerned to threaten destruction of the required assets, should the parties fail to reach agreement on the basis for cooperation. Here there is a clear asymmetry in bargaining capacities, as the South is more able to threaten destruction of its capital endowment than is the North. This is because the destruction of environmental resources is a much more credible threat than is the threat to destroy human capital. It has been noted in other contexts that destruction of resources can be used as a means of securing bargaining power. ${ }^{21}$ In the biodiversity context the strategic destruction of Reserves can be understood as a literal threat to destroy resources, as witnessed in Latin America [24] and discussed in relation to fisheries elsewhere [4], or as the static representation of a threat to allow ongoing and irreversible conversion in the absence of cooperation. Coupled with the assumption of irreversibility, the threat to destroy Reserves constitutes a 'natural' commitment mechanism which is entirely absent in the North. Consequently, given the asymmetry in capital endowments, only the South has

\footnotetext{
${ }^{17}$ Or, equivalently, increase the costs of disagreement.

${ }^{18}$ More generally, rational threats imply that prior to negotiation of the bargaining solution, parties can commit to actions to be played in the event that bargaining fails and by manipulating the conflict point in this way affect the terms of the agreement in their favour. In short, commitments are not made because the agents are interested in the conflict payoffs themselves, but rather in the effect of these strategies on the final bargaining outcome. This realisation has important implications for our understanding of the BBP by alerting us to the prospect of strategic behaviour in the search for a solution.

${ }^{19}$ Parallels can be easily drawn between this type of threat for the North and the trade restrictions and limitations on technology transfer that have been the focus of the strategic trade literature (e.g. [14], [15])

${ }^{20}$ Whereas the original stylised exposition by Nash [17] involved an imaginary 'umpire' to ensure the credibility of the threats, any application of this model requires that the threats are credible.

${ }^{21}$ The possibility of incentives for strategic destruction of environmental resources has also cited elsewhere in the context of international fisheries and other marine resources [4], [1] and forests [24]. A number of alternative game-theoretical perspectives also exist (e.g. [3]).
} 
the potential capacity to satisfy the necessary conditions for a credible threat in the BBP.

\subsubsection{BBP as an NBG with Strategic Destruction}

In this section we explore the implications for the BBP of the South's unique capacity for credibly threatening capital destruction - by establishing how this capacity is able to impact upon the distribution of power and hence possible solutions to the BBP. We model this capital destruction as the permanent loss of lands that formerly fulfilled the functions of Reserves. This implies a reduction in the land available for production: the land endowment $\left(L_{S}\right)$, and the level of Reserves $(R)$. The destruction of Reserves makes $L_{S}$ a strategic variable $^{22}$.

We model the BBP as an NBG with variable threats for the South and through this lens the BBP unfolds in the following order: i) the initial non-cooperative outcome or conflict point is determined as Autarky $\left(U^{a}\right)$; ii) the South issues its threat in the form of a land allocation in the event that cooperation fails. This involves a choice of strategic destruction $(D)$ and defines a new conflict point $\left(U^{D}\right)$; iii) the bargaining game is solved by reference to this new conflict point yielding payoffs $U_{i}^{T}$, where the superscript refers to threats. Each of these points is illustrated in Figure 2. In order for the South to strategically threaten destruction the strategy must be credible. Specifically, credibility requires that the irreversibility of resource destruction in Assumption 1 holds, and that destruction is both viable and satifies Autarky Independence.

This leads to the Definitions 1 and 2:

DEFINITION 1 (Viability): A strategic threat is viable if it could be carried out and yet leave the South with a payoff in any subsequent Nash solution no less than it could expect in the fixed threat Nash solution.

DEFINITION 2: (Autarky Independence): A strategic threat satisfies Autarky Independence if it could be carried out and yet leave the Autarky payoff no less than in the fixed threat NBG.

Since Reserves are residual to the South in Autarky, reflecting the informational nature of the goods they supply and the market failure in the Reserves market, Autarky Independence is guaranteed in the BBP so long as no disproportionate amount of ancillary resources is expended in choosing to destroying Reserves. ${ }^{23}$ Assuming cost-neutrality, strategic destruction will not reduce the South's conflict payoff.

It remains to show the viability of strategic destruction in the BBP. Proposition 2 establishes sufficient conditions for viability:

PROPOSITION 2 (Viable Strategic Destruction): Let $L_{S}^{*}$ denote the maximum level of Reserves available to the South, and let $L_{S}=L_{S}^{*}-D$ be the amount of land the South wishes to maintain, where $D$ is the amount of land destroyed. Whenever the payoff maximising solution and autarky solutions are interior solutions, a sufficient condition for the South to viably threaten positive levels of destruction are that destruction is costless, and

\footnotetext{
${ }^{22}$ We assume that destruction renders land incapable of supporting either Reserves or traditional production.

${ }^{23}$ In this model the primary factor of concern in the South is the land endowment, and in regard to this destruction of reserves is costless. In regard to ancillary resources (such as labour), the activity of destruction is not obviously more labour intensive than other uses of the land (such as conservation), and so the cost-neutrality of destruction is a reasonable assumption.
} 


$$
\pi^{\prime}\left(L_{S}^{*}-t^{a}\right)\left(n^{a}\right)>\pi^{\prime}\left(L_{S}^{*}-s^{*}-t^{*}\right)\left(n^{*}+s^{*}\right) .
$$

PROOF: See Appendix B.

If condition (20) holds, the threat to destroy Reserves is defined as viable. This means that actual destruction would increase the benefits of cooperation for the North, therefore increasing the Nash payoff for the South in any subsequent Nash bargaining game. For viability, condition (20) shows that it is sufficient that the marginal value of Reserves under the Autarky solution is higher than in the Social Planner solution. This captures the essential trade-off for the South in destroying Reserves: If Reserves were destroyed the South's share of surplus, determined by its share of global intensive production, must increase more than the loss of global surplus that would accompany destruction. Loss of productivity in the intensive sector would ensure the latter. In fact, although destruction is merely threatened here, viability can be understood by inspection of Figure 3, where the impact of destruction taking place is depicted. Here, condition (20) is illustrated by the movement of the conflict point downwards as Reserves are destroyed. This ensures that $U^{* D}$, a Nash bargaining solution subsequent to destruction, lies down and to the right of $U^{*}$, the Nash solution with fixed threats. When this condition holds, the South will be able to issue strategic threats and secure $U_{S}^{T} \cdot{ }^{24}$

\subsubsection{Contractual Solution}

We now wish to see how the availibility of viable and credible "rational threats" to one side of this bargaining problem, the South, would impact upon the contractual solutions to the problem. In effect, the availability of the threat pushes the threat point downwards from $U^{a}$ to $U^{D}$. Figure 2 shows how this can improve the outcome of the South by shifting the Nash solution from $U^{*}$ (a Nash solution without threats) to $U^{T}$ (a Nash solution with threats). The solution to the NGB with variable threats can be described more formally as above: $U_{N}^{T}=(1-\alpha) U_{N}^{D}+\alpha\left(U^{*}-U_{S}^{a}\right)$ and $U_{S}^{T}=\alpha U_{S}^{a}+(1-\alpha)\left(U^{*}-U_{N}^{D}\right)$, where $U_{N}^{D}$ represents the conflict payoff for the North given the South's threat of destruction.

As above, this solution could be upheld in practice with a contract offered either by the North or the South which includes a lump-sum payment reflecting the bargaining solution agreed under threat from the South. We continue with the North making the offer, to be consistent with the form in which Proposition was expressed. Proposition 3 makes the new contractual form concrete:

PROPOSITION 3 (The North's contract with strategic threats from South): Where the BBP is modelled as an NBG with viable and credible strategic threats, the

\footnotetext{
${ }^{24}$ Example 1 (Strategic Destruction in the BBP): Assume the following functional forms: $\pi(R)=$ $R^{\delta}$, where $\delta<1, c(x)=x^{\beta}$, where $\beta>1$ and $k(t)=t^{\gamma}$, where $\gamma>1$, and assume that $b=0$. Then for $L_{N}$ sufficiently large, destruction is worthwhile to the South if and only if:

$$
L_{S}^{*}>\left(\frac{1}{\gamma}\right)^{\gamma-1} \text { and } \beta>\frac{1}{1-\delta}
$$

PROOF: See Appendix B.

This shows how viability can depend upon the relative curvature of the seed cost and R\&D functions, $c($. and $\pi(R)$ respectively.
} 
solution can be upheld by a contract in which and the North specifies $s^{*}, n^{*}$ and offers the following transfer to the South:

$$
T_{N}\left(L_{S}, t\right)=\int_{t}^{t^{a}}\left[1-k^{\prime}(z)\right] d z-\pi\left(L_{S}-s^{*}-t\right) s^{*}+(1-\alpha)\left(U^{C D}\right)
$$

Where $U^{C D}=U^{*}-\left(U_{N}^{D}+U_{S}^{a}\right)$.

PROOF: See Appendix C.

The only difference between this contract and the general contract described in Proposition $1 \mathrm{c}$ is in the right hand side term which reflects the North's new conflict payoff, $U_{N}^{C D}$, rather than $U_{N}^{a}$. The difference between the contracts is therefore equal to $(1-\alpha)\left(U_{N}^{a}-U_{N}^{D}\right)$ and this is a measure of the impact that strategic threats have on the solution to the BBP. Explicitly, the impact can be measured by (see Appendix C) ${ }^{25}$ :

$$
(1-\alpha)\left(U_{N}^{a}-U_{N}^{D}\right)=(1-\alpha) \int_{L_{s}^{D}}^{L_{S}^{*}}\left[\pi^{\prime}\left(x-t_{a}\right) n^{a}\right] d x
$$

The contract which upholds the Nash bargaining solution with strategic threats is now dependent upon the existing stocks of Reserves through the specification of $L_{S}^{*}$. The magnitude of the payment depends upon the potential for destruction $\left(L_{S}^{D}\right)$ as well as the relative bargaining power of the South $(1-\alpha)$, and reflects a proportion of the spillover from Reserves that the North receives in Autarky. Once more, the contract ensures that the South is indifferent between any value of $t$ and $L_{S}$ including $t^{*}$ and $L_{S}^{*}$, and the efficient Nash solution can be upheld through the sharing of surplus.

The unique capacity of the South to make a viable and credible threat alters the power distribution in the relationship. The new solution to the BBP (once the threat is taken into consideration) will lie along the same bargaining frontier, but with an increased distribution of the surplus to the South. ${ }^{26}$

\subsubsection{Discussion}

There are two points to be drawn from what has been discussed here. First, in this section we have attempted to narrow down the range of potential contractual outcomes to the biodiversity bargaining problem, by considering how the asymmetries between the parties (laid out in Assumption 1) might contribute to differences in the availability of "rational threats". Although both parties make important contributions to the creation of the cooperative surplus, the fact that the endowment (the reserves) of the South is inherently and irreversibly destructible provides the South with a significant bargaining advantage. Since irreversibility is a sufficient condition for a threat to be credible, the South has the unique capacity in this context to shift surplus towards itself. ${ }^{27}$ The idea that the South has much of the bargaining power in the BBP is interesting in its own right.

\footnotetext{
${ }^{25}$ In equilibrium the compensation is the integral from $L_{S}^{*}$ to $L_{S}^{D}$. Once more $z$ is simply the argument of the integral.

${ }^{26}$ This may be conceived of as a physical endowment that contributes to the bargaining power of the S. The addition of this factor occasions a shift in outcome along the original bargaining frontier, which may be conceived of as a shift in the power coefficient (from $\alpha$ to $\alpha^{\prime}$ ) in favour of the S.

${ }^{27}$ It is interesting to note that if the threat is viable (that is, condition (20) holds), then the strategic threats are viable irrespective of the initial bargaining power situation, represented by $\alpha$. That is, even if the bargaining solution without threats significantly favours the South $(\alpha \rightarrow 0)$, the South will find it viable to
} 
Secondly, the asymmetry in physical endowments indicates the nature of the contractual terms that would be expected to result from a bargaining process based upon them. It would appear that the South should be able to exercise its unique advantage to skew the bargaining outcome in its favour. In terms of the BBP, we would anticipate that the South would be able to command a substantial share of the cooperative surplus. In addition, as (22) shows, an efficient solution to the BBP would imply that the contractual terms explicitly base compensation upon the existing level of Reserves. We turn now to examine the nature of the contracted solution concept, and how it accords with the predicted outcomes.

\section{Explaining Observed Contractual Outcomes: IC Con- tract}

We have shown that the South is the region that would be expected to hold enhanced bargaining power under the asymmetric conditions of the biodiversity bargaining problem. For this reason we would anticipate that the South would be able to achieve a contractual outcome with a significant share of the cooperative surplus, and also that this share would be made contingent upon the level of reserves it maintains. Here we show this is not a very accurate description of the prevailing institution - the Incremental Cost (IC) contract.

We argue here that, in terms of the $\mathrm{BBP}$, the $\mathrm{IC}$ contract can be explained in terms of pre-bargaining commitment by the North. That is, in the face of the distribution of power represented by rational threats of destruction by the South, the North's rational response has been to offer contracts based on institutional precedents that have little obvious application within this context. This commitment to pre-existing institutions pre-determines the contractual outcome in advance of the bargaining process, but it does not provide a likely stable outcome.

\subsection{The IC contract in the bargaining game context}

Recall from Section 1 that the IC contract offers payments from North to South of the amounts required to secure the participation of the South in the provision of the global good. Section 18 of the CBD provides that the South shall receive for its cooperation:

"[the costs of] additional national action beyond what is required for national development [the baseline] that imposes additional [or incremental] costs on countries beyond the costs that are strictly necessary for achieving their own development goals, but nevertheless generates additional benefits that the world as a whole can share ..."

It is clear that, in the language of the BBP, the IC contract requires the North to compensate the South for the additional costs it incurs by electing the cooperative development path (choosing $t^{*}$ ) rather than its baseline development strategy (choosing $t^{a}$ ). There is no allusion to or provision for enhanced sharing by the South in the cooperative surplus by reason of this election, but only provision for the compensation of its costs incurred to "generate

employ strategic threats to improve the negotiated payoff. Additionally, where the North has all the initial bargaining power $(\alpha=1)$ the South is indifferent to threatening destruction even if condition (20) does not hold. Ultimately, whatever the initial bargaining power of the North, the South can bring considerable bargaining power, in the form of strategic threats, to the negotiating table. 
additional benefits that the world as a whole can share" The South will of course obtain its share of this cooperative surplus, but the contract does not provide for any enhanced share in exchange for its cooperation, nor does it condition payment on the level of the South's Reserves. $^{28}$ The IC contract does not bear any of the hallmarks of the contract that would be anticipated to arise out of the NBG. Instead, the IC contract is a straightforward offer of the extreme point contract, in which the North offers the South compensation for its costs incurred in participating in the cooperative outcome. The puzzle of this NBG is how such an unanticipated outcome could result from this sort of bargaining problem. We turn now to analyse the possible explanations: bargaining and structure.

\subsection{Explaining the IC Contract as the Outcome of a NBG}

One possibility is that the parties engaged in bargaining, and that the North offered these terms of contract in the context of the NBG. The problem with this explanation is that the South has the option of destruction, once bargaining has commenced, and destruction is a possible outcome in the face of an offer that fails adequately to compensate the South for its bargaining position. The offering of contracts of the form shown in Proposition 1c with inadequate sharing with the South, can induce anticipatory strategic destruction by the South. The weakness of this form of contracting is that they are silent on the commitment to any level of reserves. Faced with a contract of this form, when strategic threats are viable (condition (20) holds), the South can commit to (undertake) strategic destruction ${ }^{29}$. Figure 3 illustrates this point. When destruction is viable, payoffs can be increased from $U_{S}^{*}$ with fixed threats to $U_{S}^{D}$ if anticipatory destruction is carried out, despite the inward movement of the bargaining frontier. In short, a naive approach to bargaining by the North within the $\mathrm{BBP}$ can induce destruction of Reserves ${ }^{30}$.

In contrast, optimal contracts of the form described in Proposition 3 condition payments explicitly on $L_{S}^{*}$, the socially optimal level of the South's endowment, hence removing the incentive to destroy. This can be seen by inspection of condition (22). Indeed, when the South is offered such a contract it is indifferent between any choice of $L_{S}$ and can be easily coerced into choosing $L_{S}^{*}$. The interpretation of (22) is also interesting. This implies that in order to uphold the Nash solution with variable threats the North must transfer some fraction of the positive spillover it receives in Autarky. In effect this means that the South must be paid for the stocks of Reserves it would hold in Autarky. This general recommendation accords with findings elsewhere (see e.g. [23]). Figure 2 illustrates this point: Payoffs can be increased from $U_{S}^{*}$ with fixed threats to $U_{S}^{T}$ where destruction is threatened. In this case the solution is on the efficient frontier at $U^{* T}$, the movement from $U^{*}$ reflecting the South being remunerated for stocks of Reserves.

In sum, it is unlikely that this extreme point contract could result from a bargaining

\footnotetext{
${ }^{28}$ Elsewhere in the CBD there are provisions for benefit-sharing that provide for sovereignty over national genetic resources and prior informed consent for making access to and use of these resources. We deal in companion papers with the issues surrounding the use of property rights mechanisms to distribute the cooperative surplus. ([10]; [19]) Suffice it to say that we do not find that these provisions make any significant impact on the contractual outcome observed here.

${ }^{29}$ Given our informational assumptions a contract of this form would not specify $t^{*}$ and $s^{*}$ in the final stage of the game, but the optimising values of these land allocations given destruction has taken place. This is reflected by the solution being located on a bargaining frontier that has shifted inwards in Figure 3.

${ }^{30}$ This is akin to the pre-contractual commitments in the form of sunk capital analysed by Stranlund [21]
} 
process commencing from the power distribution described in Section 3. Even if the North has the capacity to make the initial offer of the IC contract, it is not a stable outcome of the bargaining game. The South retains bargaining leverage that would imply that outcomes nearer those detailed at the end of section 3 would result.

\subsection{Explaining IC Contract as Institutional Pre-Commitment}

The distribution of bargaining power between the parties renders the bargaining process within the BBP a place with clear leverage for the South but little obvious source of power for the North. Given that the North has the foresight to see the implications of these asymmetric endowments for the BBP, it may be inclined to circumvent the Nash bargaining agreement altogether by pre-committing to an alternative institution. Pre-bargaining commitments in the resolution of environmental conflicts have been analysed elsewhere in relation to international agreements ([21], [12]). In such cases, irreversible (sunk) capital investments are crucial in determining the eventual terms of the agreement. In the case of the BBP, the nature of pre-commitment is institutional. Specifically, we argue here that the North was able to select and commit to its preferred institutional form prior to bargaining, in order to target contractual terms that are both capable of attaining its preferred extreme point solution and of doing so in such a manner as to nullify the capacity for strategic destruction in the South.

In terms of Figures 2 and 3, in the Nash solution in which strategic destruction is viable and credible, the North will obtain the payoff $U_{N}^{T}$ where information is complete and destruction is threatened, and $U_{N}^{* D}$ when anticipatory destruction takes place. Given our assumptions on viability, the North is worse off in both cases than in the absence of strategic destruction: $U_{N}^{*}>U_{N}^{T}>U_{N}^{* D}$. Contracts such as in Proposition 1c could lead to inefficiency, while the efficient contract of Proposition 3 would tend to distribute the surplus away from the North. The obvious solution for North is to maximise its payoff by pre-commitment to the extreme point contract of Proposition 1(b). However, unlike the more general contract of 1(c), this contract has the additional advantage of rendering the South indifferent over destruction. So, through commitment, the North is able to attain its first-best outcome while negating the incentives for inefficient bargaining.

The North was able to achieve pre-commitment in this context through the vehicle of the pre-existing institutional commitment to the Montreal Protocol. This international environmental agreement was developed over the decade of the 1980s for the purpose of controlling emissions of those chemical substances with deleterious effects upon the ozone layer. That international agreement was based on entirely distinct initial conditions and endowments, and there was no obvious reason why its solution concept would have any application within the context of the BBP. In the first instance, there was far more symmetry in initial conditions, in that the global public good existed outside any party's territory so that each party had a symmetric interest in its use or destruction. In addition, given the atmospheric nature of the good, the capacities to harm the good were largely symmetric and reciprocal (at least in the medium run). Finally, it was even possible that damage to the atmospheric good was potentially reversible with a halt in ongoing impacts. In many ways the initial conditions and physical endowments regarding chemical industries and ozone depletion generate a bargaining game that could not be more different in its basic nature than the BBP. 
Nevertheless, the North managed to pre-commit prior to the BBP to the contractual terms developed within negotiations concerning the Montreal Protocol. ${ }^{31}$ The concept of IC was developed within the financial mechanism of the Montreal Protocol (where the text was first written in the mid-1980s and then made effective in 1989) and then extended to the BBP by its express incorporation within the terms of the CBD in 1992 [Art 20 above][13]. There is no reason in logic for the straightforward extension of one bargaining outcome to a very different context; however, the assertion of the precedential value of this concept for the compensation of global public goods was able to establish the institution as a pre-commitment. Its extension to the BBP represents an institutional pre-emption of the bargaining game that would otherwise have resulted.

\subsection{Structure over Power: The Outcome of the BBP}

In sum, the explanation for the IC framework adopted within the CBD appears to lie within the bargaining structure of the problem rather than in the prevailing power distribution regarding biodiversity. The North has been able to assert pre-commitment to a concept for compensating global public goods that, irrespective of its applicability in the context of the ozone layer, clearly had little relevance to the BBP. Such pre-commitment would appear to be a rational approach, given the asymmetry of bargaining power between North and South and the lack of advantages to the North from pursuing the cooperative bargaining outcome.

The problem with this approach to the resolution of the BBP is that it ignores the underlying realities of the context. A contract based on pre-commitment and participation payments is a flimsy basis for an enduring solution to the problem. The South retains its fundamental differences and the contributions to bargaining power that they represent. This means that, on any occasion that bargaining is re-opened, the threat of destruction remains a real possibility. Since the South is merely indifferent between the current outcome and any other, the likelihood that IC is a stable outcome is very small indeed.

\section{Conclusion}

This paper has examined the prevailing solution to the international biodiversity bargaining problem building on the insights of bargaining theory and rational threats. The prevailing solution is of interest to students of international cooperation over global environmental goods: While the existence of a solution to the BBP has its natural explanation in the gains from cooperation that are available to the contracting parties, the specific form of the contractual solution is not obvious. We find that the emergence of the IC contract is both surprising and instructive for understanding the nature of North-South cooperation over global environmental goods. It is surprising because on the basis of this stylized model, we find an asymmetry in regional endowments that would have us predict a power distribution that would instead more favour the South.

The institutional analysis of the outcome of the BBP is instructive since it demonstrates the differential capacity for agenda-setting between the parties. Despite being disadvantaged by the nature of the regional endowments at its disposal, the North has been able to obtain

\footnotetext{
31 "The application of incremental cost in the Montreal Protocol influenced the development of the subsequent global environmental conventions...".[6]
} 
an extreme point contract by virtue of being able to pre-commit to the institution prior to bargaining being undertaken. This asymmetry in institutional power, and its ability to counter-balance the advantages deriving from other endowments, is the explanation of how structure has managed to prevail over bargaining power. However, this also indicates that there is a fundamental contradiction inherent within the current contract, and that the current outcome may not be a stable one

\section{References}

[1] Barrett, S (2002). Environment and Statecraft. Oxford University Press Inc, New York.

[2] Barrett, S (1994): The Biodiversity Supergame Environmental and Resource Economics, vol. 4(1), pp. 111-122

[3] Ben Porath E and Dekel E (1992): Signalling future actions and the potential for sacrifice. J. Econom. Theory 57: 36-51.

[4] Copeland, B. R. (1990). Strategic enhancement and destruction of fisheries and the environment in the presence of international externalities. J. Environ. Econom, Management, 19(3), p213-226.

[5] Droege, S. and Soete, B. (2001): Trade-Related Intellectual Property Rights, NorthSouth Trade and Biological Diversity. Environmental and Resource Economics 19: p149163.

[6] GEF (2005). The Evaluation of GEF Incremental Cost Methodologies. GEF Evaluation Office, http://www.gefweb.org/MonitoringandEvaluation/MEOngoingEvaluations/ documents/Ongoing_Evals-GEF_Incremental_Cost_Method-Approach_Paper.pdf

[7] Goeschl, T. and Swanson, T. (2002): The Social Value of Biodiversity for R\&D. Environmental and Resource Economics 22(4):1-28.

[8] Goeschl, T and Swanson, T. (2003a): On Biology and Technology: The Economics of Managing Biotechnologies. The Fondazione Eni Enrico Mattei (FEEM) Note di Lavoro Series \#42.03.

[9] Goeschl, T and Swanson, T (2003b). Pests, Plagues, and Patents. J. European Economic Association. Vol 1(2), pp.561-575.

[10] Groom B, Gatti J R J, Goeschl T and Swanson T (2006). Contracting on Biodiversity Outputs: IPRs as a solution to the Biodiversity Bargaining Problem. School of Oriental and African Studies Working Paper.

[11] Helpman E (1993). Innovation, Imitation, and Intellectual Property Rights. Econometrica $61, \mathrm{p} 1247-1280$.

[12] Jerrell R and Stranlund J K (1997). Threat Positions and the Resolution of Environmental Conflicts. Land Economics 73(1), pp 58-71 
[13] King, K (1994). The Incremental Costs of Global Environmental Benefits. GEF Discussion Paper 94-05, Washington DC.

[14] Krugman, P (1979). A Model of Innovation, Technology Transfer, and the World Distribution of Income. J. Political Economy, Vol. 87 (2) pp. 253-66.

[15] Lai E and Qiu L (2003). The North's Property Rights Standard for the South. J. International Economics. 59, pp183-209.

[16] Leakey, R and Lewin, R. (1995). The Sixth Extinction. Weidenfeld and Nicolson, London

[17] Nash J (1953). Two-Person Cooperative Games. Econometrica Vol 21(1), pp128-140.

[18] Polasky, S; Costello, C; McAusland, C (2004). On trade, land-use and biodiversity. J. Environ. Econom., Management, 48(2), pp.911-925, 2004.

[19] Sarr M and Swanson T (2006). The Economics of IPR for Bioprospecting - Considering the Importance of Property Rights Placement. Department of Economics, University College London. mimeo

[20] Simpson, R.D., Sedjo, R.A. \& Reid J.W. (1996) Valuing Biodiversity for Use in Pharmaceutical Research. J. Political Economy. 104, pp163-185.

[21] Stranlund, J K (1999). Sunk Capital and Resolutions of Environmental Conflicts. Land Economics, 75(1), pp142-155.

[22] Swanson, T (1996): The Reliance of Northern Economies on Southern Biodiversity: Biodiversity as Information. Ecological Economics 17(1), pp. 1-8.

[23] van Soest D.P. and Lensink R. (2000). Foreign transfers and tropical deforestation: What terms of conditionality?. Amer. J.Agricultural Economics, 82 (May) pp389-399.

[24] World Bank (2003). Contracting for Biodiversity Conservation in Agricultural Landscapes. Environment Department Paper No.96. Environmental Economics Series, World Bank.

\section{Appendices}

\section{A Proof of Proposition 1}

b) If the North selects $\widetilde{s}$ and $\widetilde{t^{32}}$ :

$$
\begin{aligned}
T_{N}(t & : \widetilde{s}, \widetilde{t})=\int_{t}^{t^{a}}\left[1-k^{\prime}(x)\right] d x-\pi\left(L_{S}-\widetilde{s}-t\right) \widetilde{s} \\
& =\left[t^{a}-t\right]-\left[k\left(t^{a}\right)-k(t)\right]-\pi\left(L_{S}-\widetilde{s}-t\right) \widetilde{s}
\end{aligned}
$$

\footnotetext{
${ }^{32} \mathrm{An}$ analogous proof is available from the authors for the case when bargaining power is reversed.
} 
Then the South's utility is given by:

$$
\begin{aligned}
U_{S}(t) & =\pi\left(L_{S}-\widetilde{s}-t\right) \widetilde{s}+t-k(t)+T_{N}(t: \widetilde{s}, \widetilde{t}) \\
& =U_{S}^{a}
\end{aligned}
$$

Hence the South is indifferent to any level of $t$ including $\widetilde{t}$. A small penalty for deviation from $\widetilde{t}$ ensures compliance. Given the South selects $\widetilde{t}$ the North's problem is to select $(n, s, R, t)$ to maximise:

$$
\begin{aligned}
U_{N}(n, s, R, t) & =(\pi(R)-b) n-c(n+s)-T_{N}(t: s, t) \\
& =U^{*}-U_{S}^{a}=U^{C}+U_{N}^{a}
\end{aligned}
$$

This is equivalent to the Social Planner problem and the solution is $\left(n^{*}, s^{*}, R^{*}, t^{*}\right)$.

c) If the North selects $\tilde{s}$ and $\tilde{t}$ and the transfer:

$$
\begin{aligned}
T_{N}(t & : \widetilde{s}, \widetilde{t})=\int_{t}^{t^{a}}\left[1-k^{\prime}(x)\right] d x-\pi\left(L_{S}-\widetilde{s}-t\right) \widetilde{s}+(1-\alpha)\left(U^{*}-\left(U_{N}+U_{S}^{a}\right)\right) \\
& =\int_{t}^{t^{a}}\left[1-k^{\prime}(x)\right] d x-(1-\alpha) U_{S}^{a}-\pi\left(L_{S}-\widetilde{s}-t\right) \widetilde{s}+(1-\alpha)\left(U^{*}-U_{N}^{a}\right) \\
& =\alpha \int_{t^{*}}^{t^{a}}\left[1-k^{\prime}(x)\right] d x+\int_{t}^{t^{*}}\left[1-k^{\prime}(x)\right] d x-\pi\left(L_{S}-\widetilde{s}-t\right) \widetilde{s}+(1-\alpha)\left(U^{*}-U_{N}^{a}\right) \\
& =\alpha\left(t^{a}-t^{*}-\left[k\left(t^{a}\right)-k\left(t^{*}\right)\right]\right)+\left(t^{*}-t-\left[k\left(t^{*}\right)-k(t)\right]\right)-\pi\left(L_{S}-\widetilde{s}-t\right) \widetilde{s}+(1-\alpha)\left(U^{*}-U_{N}^{a}\right)
\end{aligned}
$$

Noting that $U_{S}^{a}=t^{a}-k\left(t^{a}\right)$. Then the South's utility is given by the Nash solution, $U_{S}^{*}$ :

$$
\begin{aligned}
U_{S}(t) & =\pi\left(L_{S}-\widetilde{s}-t\right) \widetilde{s}+t-k(t)+T_{N}(t: \widetilde{s}, \tilde{t}) \\
& =\alpha U_{S}^{a}+(1-\alpha)\left(\pi\left(L_{S}-\tilde{s}-t\right)(\tilde{n}+\tilde{s})-c(\tilde{n}+\tilde{s})+\tilde{t}-k(\tilde{t})-U_{N}^{a}\right) \\
& =U_{S}^{*}
\end{aligned}
$$

As before the South is now indifferent between all values of $t$ including $\tilde{t}$. Once again, a small penalty for deviation from $\widetilde{t}$ ensures compliance.

\section{B Proof of Example 1: Strategic Destruction by the South}

\section{GENERAL FORMULATION:}

$$
\frac{d U_{S}^{*}}{d L_{S}}=\alpha \frac{d U_{S}^{a}}{d L_{S}}+(1-\alpha) \frac{d\left(U^{*}-U_{N}^{a}\right)}{d L_{S}}
$$


For $L_{S}>t^{a}$, from Equation (19) $\frac{d U_{S}^{a}}{d L_{S}}=0$, and $\frac{d U_{S}^{*}}{d L_{S}}=(1-\alpha) \frac{d\left(U^{*}-U_{N}^{a}\right)}{d L_{S}}$. Therefore for all $\alpha>0, \frac{d U_{S}^{*}}{d L_{S}} \gtreqless .0$ iff $\frac{d\left(U^{*}-U_{N}^{a}\right)}{d L_{S}} \gtreqless 0$ and $U_{S}^{*}$ is maximised when $\left(U^{*}-U_{N}^{a}\right)$ is maximised, irrespective of the value of $\alpha$. From equations (14) and (11) and the Envelope Theorem:

$$
\begin{aligned}
\frac{d\left(U^{*}-U_{N}^{a}\right)}{d L_{S}} & =\frac{\partial U}{\partial L_{S}}\left(n^{*}, s^{*}, t^{*}\right)-\frac{\partial U_{N}^{a}}{\partial L_{S}}\left(n^{a}, t^{a}\right) \\
& =\pi^{\prime}\left(L_{S}-s^{*}-t^{*}\right)\left(n^{*}+s^{*}\right)-\pi^{\prime}\left(L_{S}-t^{a}\right)\left(n^{a}\right)
\end{aligned}
$$

and so

$$
\pi^{\prime}\left(\overline{L_{S}}-t^{*}\right)\left(n^{a}\right)>\pi^{\prime}\left(\overline{L_{S}}-s^{*}-t^{*}\right)\left(n^{*}+s^{*}\right) \Rightarrow \frac{d\left(U^{*}-U_{N}^{a}\right)}{d L_{S}}<0 \text { at } \overline{L_{S}}
$$

and destruction of arable land will increase Utility for the South. QED

PROOF OF EXAMPLE 1: >From Equation (15) \& (16) we have $s^{*}=0($ as $b=0)$ and $n^{*}=\left(\frac{\left(L_{S}-t^{*}\right)^{\delta}}{\beta}\right)^{\frac{1}{\beta-1}}>0$ when $L_{N}>n^{*}$. Let $\Phi\left(L_{S}, t, n\right)=\pi^{\prime}\left(L_{S}-t\right)(n)=\delta\left(L_{S}-\right.$ $t)^{\delta-1}\left(\frac{\left(L_{S}-t\right)^{\delta}}{\beta}\right)^{\frac{1}{\beta-1}}=\left(\frac{\delta}{\beta^{\frac{1}{\beta-1}}}\right)\left(L_{S}-t\right)^{\delta-1+\frac{\delta}{\beta-1}}$. Destruction is beneficial to the South if, $\overline{L_{S}}>$ $t^{a}=\left(\frac{1}{\gamma}\right)^{\gamma-1}$ and $\frac{d\left(U^{*}-U_{N}^{a}\right)}{d L_{S}}<0$ at $\overline{L_{S}}$. The last condition requires that $\Phi\left(\overline{L_{S}}, t^{a}, n^{a}\right)>$ $\Phi\left(\overline{L_{S}}, t^{*}, n^{*}\right)$

$$
\Longleftrightarrow\left(\frac{\delta}{\beta^{\frac{1}{\beta-1}}}\right)\left(\overline{L_{S}}-t^{a}\right)^{\delta-1+\frac{\delta}{\beta-1}}>\left(\frac{\delta}{\beta^{\frac{1}{\beta-1}}}\right)\left(\overline{L_{S}}-t^{*}\right)^{\delta-1+\frac{\delta}{\beta-1}}
$$

given that $t^{a}>t^{*}$, this inequality hold iff $\left(\delta-1+\frac{\delta}{\beta-1}\right)<0 \Leftrightarrow \beta>\frac{1}{1-\delta}$

\section{Proof of Proposition 3:}

The proof follows that of Appendix A only replacing $U_{N}^{a}$ with $U_{N}^{D}$. Equation (22) holds because $U_{N}^{a}=\pi\left(L_{S}^{*}-t^{a}\right) n^{a}-c\left(n^{a}\right)$ and $U_{N}^{D}=\pi\left(L_{S}^{D}-t^{a}\right) n^{a}-c\left(n^{a}\right)$. 


\section{Figures}

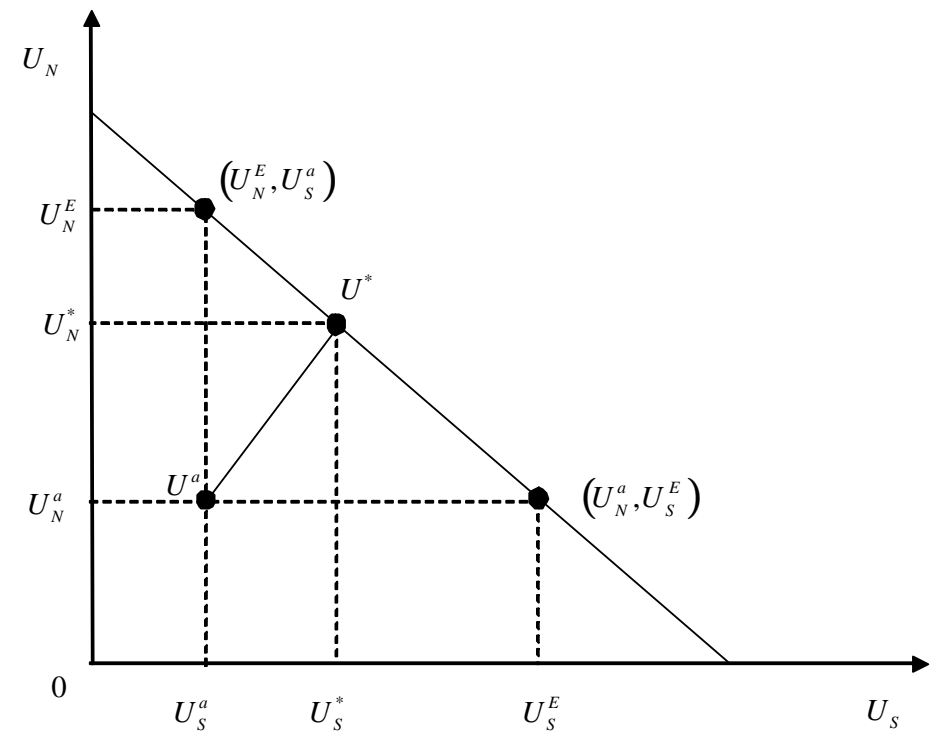

Figure 1: The Fixed Threat Nash BBP. 


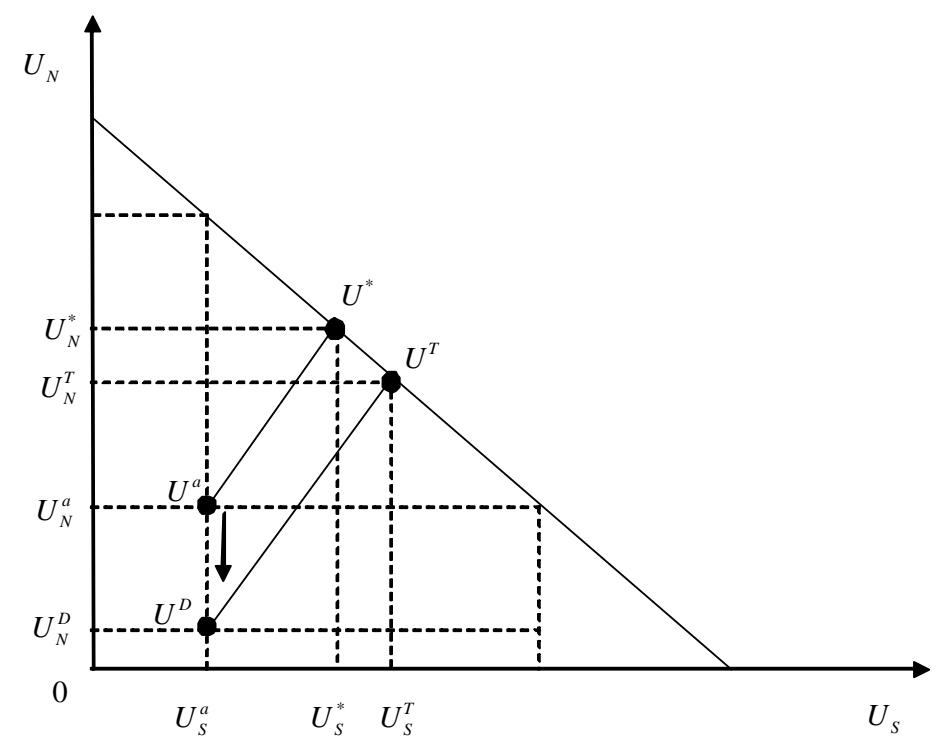

Figure 2: The Variable Threat Nash BBP.

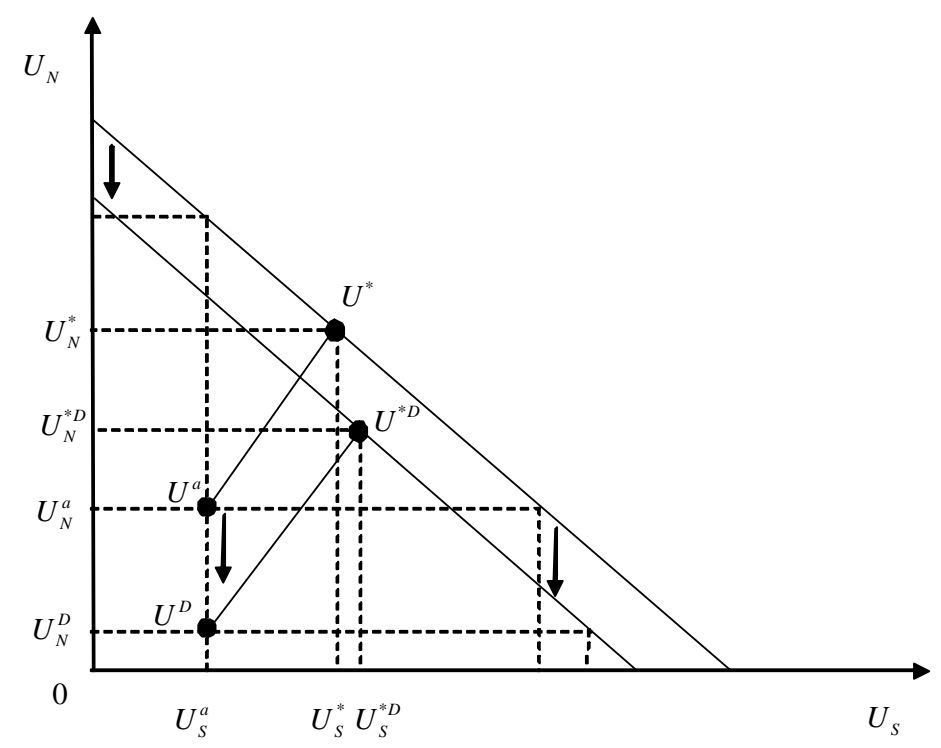

Figure 3: Pre-Contractual Strategic Destruction. 